\title{
The effect of drug habituation before and after taste aversion learning in rats
}

\author{
ERIC W. HOLMAN \\ University of California, Los Angeles, Los Angeles, California 90024
}

\begin{abstract}
In Experiment I, rats received eight habituation injections of either lithium chloride (LiCl) or sodium chloride $(\mathrm{NaCl})$, then two aversion training trials in which access to saccharin solution was followed by $\mathrm{LiCl}$ injections, and finally eight extinction trials with saccharin but no injections. The rats habituated to $\mathrm{LiCl}$ showed less aversion to saccharin during training and extinction. In Experiment II, rats received two aversion training trials, then eight habituation trials to either $\mathrm{LiCl}$ or $\mathrm{NaCl}$, then eight extinction trials, four more aversion training trials, and eight more extinction trials. The rats habituated to $\mathrm{LiCl}$ did not differ during the first extinction period from those habituated to $\mathrm{NaCl}$, but showed less aversion to saccharin during the second training and extinction periods. Consequently, habituation to $\mathrm{LiCl}$ reduces the learning of an aversion to saccharin but does not reduce the performance of a previously learned aversion.
\end{abstract}

Habituation to a stimulus tends to diminish its effectiveness as a reinforcer for subsequent learning. For instance, Church (1969) concluded that habituation to electric shock reduced the punishing effect of later stronger shocks. According to Mis and Moore (1973) and Siegel and Domjan (1971), habituation to shock retarded subsequent nictitating membrane and eyelid conditioning reinforced by shock. Kremer (1971), Rescorla (1973), and Siegel and Domjan (1971) found that habituation to shock or loud noise attenuated the ability of a stimulus subsequently paired with the shock or noise to suppress barpressing for food. In the experiments of Brookshire and Brackbill $(1971,1976)$, Cannon, Berman, Baker, and Atkinson (1975), Elkins (1974), and LeBlanc and Cappell (1974), habituation to apomorphine, ethanol, lithium chloride ( $\mathrm{LiCl})$, cyclophosphamide, morphine, or amphetamine reduced the subsequent efficacy of these drugs in reinforcing aversions to saccharin.

Habituation to the reinforcer after learning, however, may or may not reduce the conditioned responses shown in a subsequent test. When Rescorla (1973) habituated rats to a loud noise after pairing the noise with a light, the habituation hastened later extinction of conditioned suppression in the light. On the other hand, when Brookshire and Brackbill $(1971,1976)$ habituated rats to apomorphine after pairing apomorphine with saccharin, the habituation did not appreciably affect the aversion to saccharin.

This work was supported by University of California, Los Angeles, Academic Senate Grant 2386. I would like to thank Clifford Jones, Murray Reicher, and Barry Trunk for their help in running the present experiments and several preliminary studies, and Robert M. Brackbill and Dale Cannon for their comments and suggestions on the paper. Requests for reprints should be sent to Eric W. Holman, Department of Psychology, University of California, Los Angeles, California 90024.
The different effects of habituation to apomorphine before and after aversion training suggest that such habituation may influence learning rather than pêformance of the aversion.

Unfortunately, this interpretation can be questioned on the grounds that the same stimuli presented for habituation before and after training are necessarily superimposed upon different baselines of previous stimulus presentations. Suppose, for specificity, that $\mathrm{m}$ habituation trials and $\mathrm{n}$ training trials are given. If habituation occurs before training, then the habituation and control groups have had, respectively, $m$ and 0 stimulus presentations before this difference can start influencing learning. If habituation occurs after training, however, then the two groups have had, respectively, $m+n$ and n stimulus presentations before a difference in performance is tested. Thus, if habituation has some effect on learning and if habituation is asymptotic within $n$ trials, then a difference will appear in the first experiment and not the second, whether or not habituation has any additional effect on performance. Fortunately, this possibility can be tested directly, by adding a retraining phase after the extinction test in the second experiment. If the groups differ during or after retraining, then habituation cannot have become asymptotic in the $n$ original training trials. In this case, negative results in the previous extinction test are reasonably attributable to the absence of an effect of habituation on performance.

The present paper reports two experiments similar in design to the ones just outlined. The reinforcer was $\mathrm{LiCl}$, and the response was aversion to saccharin. In Experiment I, habituation to $\mathrm{LiCl}$ preceded aversion training and extinction; in Experiment II, habituation followed aversion training and preceded extinction, retraining, and reextinction. 


\section{EXPERIMENT I}

\section{Method}

The subjects were 19 naive female Sprague-Dawley rats obtained at the age of about 90 days from Simonson Laboratorles, Gilroy, California. They lived in individual cages with constant temperature and illumination and had free access to Purna Lab Chow. For 2 weeks before the experiment, they were handled daily; during the experiment, they were weighed daily before the other experimental procedures were carried out.

During habituation, the rats continued to have free access to water. They were divided into a habituation group of 10 subjects and a control group of 9 subjects. On Days 1 through 8 of the experiment, the habituation rats were given daily intraperitoneal injections of $5 \mathrm{ml}$ of $.15 \mathrm{M} \mathrm{LiCl}$; the control rats were given daily intraperitoneal injections of $5 \mathrm{ml}$ of $.15 \mathrm{M}$ sodium chloride $(\mathrm{NaCl})$. Otherwise, both groups were treated alıke throughout the experiment.

For aversion training and extinction, the rats were deprived of water on Day 10. On Days 11 through 16 and on even-numbered days thereafter, they were offered $40 \mathrm{ml}$ of water in graduated test tubes with drinking spouts, attached to the front of their home cages for $30 \mathrm{~min}$. On odd-numbered days, startıng with Day 17 , they were offered $40 \mathrm{ml}$ of $0.16 \%$ sodium saccharin solution, also in test tubes attached to their cages for $30 \mathrm{~min}$. On Days 17 and 19, they were given intraperitoneal injections of $5 \mathrm{ml}$ of $.15 \mathrm{M} \mathrm{LiCl}$ withın $5 \mathrm{~min}$ after the saccharin solution was removed. After two training trials and eight extinction trials, the experiment ended on Day 35.

\section{Results}

Figure 1 gives the mean intake of water and saccharin by both groups on all days of fluid deprivation. Before the first training injection, the groups did not differ significantly, either in total 'water intake on Days 11 through $16[t(17)=.5],{ }^{1}$ or in saccharin intake on Day $17[t(17)=0]$. Thereafter, as expected, the habituation group drank significantly more saccharin than the control group on Days 19 through $35[\mathrm{t}(17)=2.5]$. The control group compensated by drinking significantly more water than the habituation group on Days 18 through $34[\mathrm{t}(17)=2.5]$. The two groups remained about the same as each other in mean body weight, except that the control group lost slightly more weight early in extinction, when they were drinking less.

\section{EXPERIMENT II}

\section{Method}

The subjects were 25 female rats of the same age, strain, and origin as in Experıment I. They were housed, fed, handled, and weighed as in Experiment I. The saccharin solution, test tubes, and $\mathrm{LiCl}$ and $\mathrm{NaCl}$ injections were the same as in Experiment $\mathrm{I}$.

For the initial aversion training, the rats were deprived of water on the day before the experiment started. On Days 1 through 6 and 8 , they were offered $40 \mathrm{ml}$ of water for 30 min. On Days 7 and 9 , they were offered $40 \mathrm{ml}$ of saccharin for $30 \mathrm{~min}$, and then given $\mathrm{LiCl}$ injections within $5 \mathrm{~min}$ after the saccharin was removed.

For habituation, the rats were given free access to water starting on Day 10. They were divided into a habituation group of 13 subjects and a control group of 12 subjects. On Days 13 through 20 , the habituation and control rats were given daily injections of $\mathrm{LiCl}$ and $\mathrm{NaCl}$, respectively. Otherwise, both groups were treated alike throughout the experiment.

For initial extinction, retraining, and reextinction of the aversion, the rats were again deprived of water on Day 22. On Days 23 through 28 and on even-numbered days thereafter, they were offered $40 \mathrm{ml}$ of water for $30 \mathrm{~min}$. On odd-numbered days starting with Day 29, they were offered $40 \mathrm{ml}$ of saccharin solution for $30 \mathrm{~min}$. On Days $45,47,49$, and 51 , they were given $\mathrm{LiCl}$ injections within $5 \mathrm{~min}$ after the saccharin solution was removed. After eight initial extinction trials, four retrainıng trials, and eight reextinction trials, the experiment ended on Day 67. Retraining involved more trials than initial training, because saccharin was familiar by then, and familiar flavors are less subject to aversion than novel flavors according to Revusky and Bedarf (1967).

\section{Results}

Figure 2 gives the mean intake of water and saccharin by both groups on all days of deprivation. The groups were of course equivalent before habituation. After habituation, the groups did not differ in water intake on Days 23 through 28 before initial extinction $[\mathrm{t}(23)=1.2]$, on Days 30 through 44 during initial extinction $[\mathrm{t}(23)=1.0]$, or on Days 46

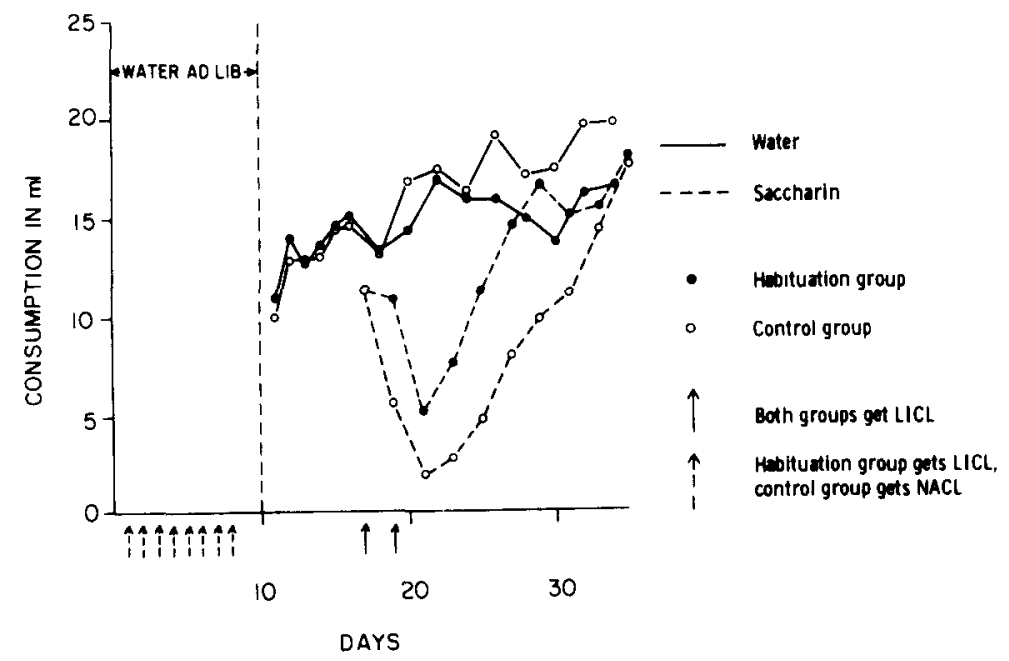

Figure 1. Mean daily consumption of water and saccharin solution in Experiment I. 


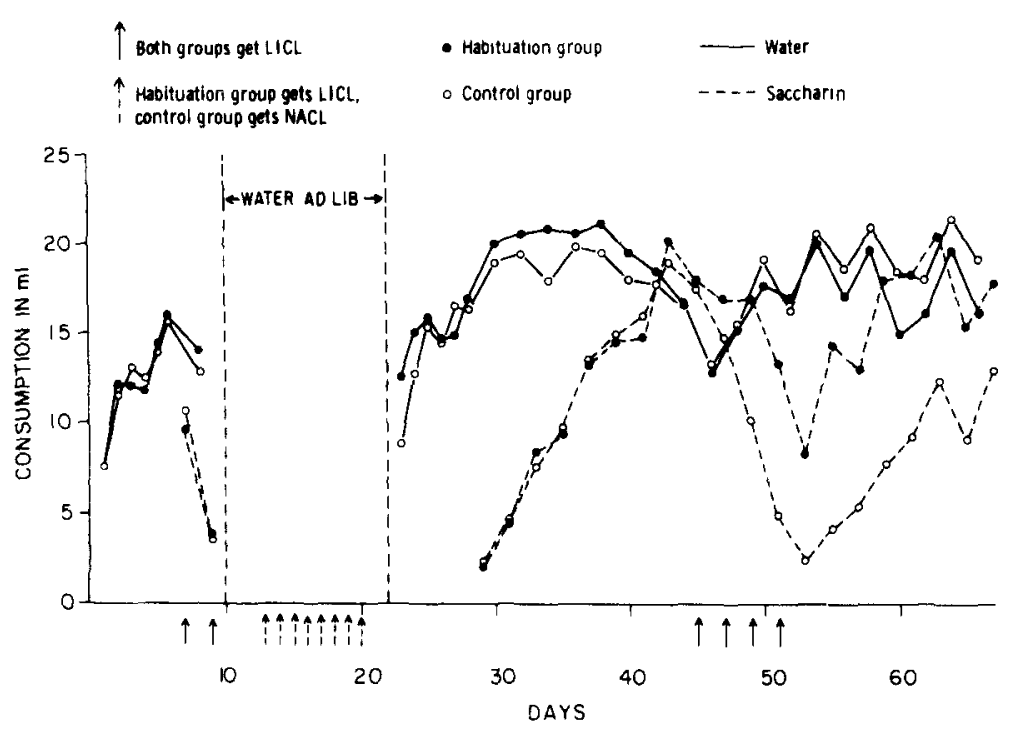

Figure 2. Mean daily consumption of water and saccharin solution in Experiment II. through 66 during retraining and reextinction $[\mathrm{t}(23)=1.0]$. Nor did the groups differ in saccharin intake on Days 29 through 45 before the first retraining injection $[t(23)=.03]$. Thereafter, as in Experiment I, the habituation group drank significantly more saccharin than the control group $[\mathrm{t}(23)=4.5]$. The two groups again remained about the same as each other in mean body weight, except that the control group lost slightly more weight late in retraining and in reextinction, when they were drinking less.

\section{GENERAL DISCUSSION}

Habituation to $\mathrm{LiCl}$ reduced the learning or relearning of a saccharin aversion reinforced with $\mathrm{LiCl}$ after habituation. This finding confirms and extends the effect of $\mathrm{LiCl}$ habituation reported by Cannon et al. (1975). In their Experiment 2, a single habituation trial was effective in reducing aversion when aversion training began 1 day later but not when training began 4 or 8 days later. In the present study, eight habituation trials reduced aversion when training began 9 days later in Experiment $I$ and when retraining began 25 days later in Experiment II. Not surprisingly, therefore, more extensive habituation has more durable effects.

Habituation to $\mathrm{LiCl}$ did not, however, reduce the performance of a saccharin aversion reinforced with $\mathrm{LiCl}$ before habituation. This finding corroborates with a different drug the effect of apomorphine habituation reported by Brookshire and Brackbill $(1971,1976)$. Moreover, the present negative result cannot be attributed to asymptotic habituation in both groups, since the groups differed in subsequent reconditioning.

In these experiments as in previous ones, there is no evidence that the effects of habituation were mediated by aversion to the food and water that were available during habituation trials; the groups did not differ in water intake or body weight until after differences in saccharin intake had already appeared. Nor did the habituation reduce sensitivity to the taste of saccharin or ability to suppress drinking; the groups did not differ in saccharin intake on the first training trial in Experiment $I$ or during the first extinction period in Experiment II. Instead, the effect of habituation seemed to be directly upon the capacity of the drug to reinforce the aversion.

The negligible effect of drug habituation on aversion performance as distinguished from reinforcement stands in contrast to the substantial effect found by Rescorla (1973) of habituation to noise on the performance of conditioned suppression. At least three classes of explanation for this difference are possible. First, there are parametric differences between the experiments: for instance, the effective intensities of the noise and drug reinforcers may have been quite different; also Rescorla ran several trials per day while taste aversion experiments use only one daily trial. Second, habituation to noise and to drugs may involve different mechanisms despite their operational similarity. Finally, Rozin and Kalat (1971) have suggested that taste aversion learning may have special properties not shared by learning about exteroceptive stimuli; the differing effects of habituation may reflect these special properties.

The present experiments suggest a possible explanation for the finding of Garb and Stunkard (1974) that people are more likely to form taste aversions in childhood than in adulthood, as well as the more informal generalization that food habits learned early in life are difficult to change later. At first, the postingestive effects associated either intrinsically or adventitiously with different foods will not have been habituated and should therefore be relatively potent in producing preferences 
and aversions. Later experience with these effects should produce increasing habituation. According to the present experimenis, this habituation should reduce the ability of postingestive effects to alter preferences and aversions, but should not diminish preferences and aversions already learned.

\section{REFERENCES}

BroOKSHIRE, K. H., \& BRACKBILL, R. M. Habituation to illness: Effects on acquisition and retention of a conditioned taste aversion. Psychonomic Science, 1971, 25, 52. (Abstract)

BrookshiRe, K. H., \& BRACKBILL, R. M. Formation and retention of conditionod taste aversions and UCS habituation. Bulletin of the Psychonomic Society, 1976, 7, 125-128.

Cannon, D. S., Berman, R. F., Baker, T. B., \& Atkinson, C. A. Effects of preconditioning unconditioned stimulus experience on learned taste aversions. Joumal of Experimental Psychology" Animal Behavior Processes, 1975, 1, 270-284.

Church, R. M. Response suppression. In B. A. Campbell and R. M. Church (Eds.), Punishment and aversive behavior. New York: Appleton-Century-Crofts, 1969.

Elkins, R. L. Bait-shyness acquisition and resistance to extinction as functions of US exposure prior to conditioning. Physiological Psychology, 1974, 2, 341-343.

GARB, J. L., \& StunkaRd, A. J. Taste aversions in man. American Journal of Psychiatry, 1974, 131, 1204-1207.

KREMER, E. F. Truly random and traditional control procedures
In CER conditioning in the rat. Joumal of Comparative and Physiological Psychology, 1971, 76, 441.448.

LeBlanc, A. E., \& Cappeli., H. Attenuation of punishing effects of morphine and amphetamine by chronic prior treatment. Joumal of Comparative and Physiological Psychology, 1974, 87, 691.698.

MIs, R. W., \& Moore, J. W. Effects of preacquisition UCS exposure on classical conditioning of the rabbit's nictitating membrane response. Learning and Motivation, 1973, 4, 108-114.

RESCORLA, R. A. Effect of US habituation following conditioning. Journal of Comparative and Physiological Psychology, 1973, 82, 137-143.

REVusky, S. H., \& BEDARF, E. W. Association of illness with prior ingestion of novel foods. Science, 1967, 155, 219-220.

Rozin, P..\& Kalat, J. W. Specific hungers and poison avoidance as adaptive specializations of learning. Psychological Review, $1971,78,459-486$.

Siegel, S., \& Domjan, M. Backward conditioning as an inhibitory procedure. Learning and Motivation, 1971. 2, $1-11$.

\section{NOTE}

1. All statistical tests in this paper use the .05 level of significance.

(Received for publication September 22, 1975; revision accepted January $21,1976$. 